\title{
New political economies of film distribution for South Africa's townships? A critical survey of the ReaGilè concept
}

\author{
Nyasha Mboti and Keyan Tomaselli
}

\begin{abstract}
ReaGilès are pre-fabricated, self-contained, education and entertainment complexes situated on $400 \mathrm{~m}^{2}$ sites at local schools or public open spaces consisting of a 60-seat cinema, 30seat computer and Internet facility, community care and policing centre. These complexes intended to service historically underserviced peri-urban black dormitory townships, and to help create jobs, especially amongst the youth, women and the disabled. The ReaGilè concept has the potential to revolutionise exhibition and distribution in local film industries in ways mirroring the ground-breaking Nollywood straight-to-DVD model. The article discusses the potential of the ReaGilè concept to offer solutions to the twin crises of 1) representation stemming from existing film distribution networks that limit micro-budget filmmakers and, 2) of government departments and local municipalities' tendency towards dividing practices that objectivise the subject through frustrating development via delays, paperwork, never-ending meetings, fees, endless formalities and legalities, and red tape. The authors posit that ReaGilè has the potential to creatively redesign formal distribution models and to fracture the narrow modernisation paradigm they deploy, replacing them with a responsive communication re/ordering and flexible distribution that restores subjectivity to the disenfranchised South African subject (the filmmaker from the township).
\end{abstract}

Keywords: film distribution, path dependency, ReaGilè, South African townships

Nyasha Mboti is Professor at the School of Communication, University of Johannesburg. nmboti@uj.ac.za; Keyan Tomaselli is Distinguished Professor at the University of Johannesburg. keyant@uj.ac.za
$Q_{\text {critical arts }}$
Routledge
UNISA
ISSN 0256-0046/Online 1992-6049 pp.621-643
DOI: $10.1080 / 02560046.2015 .1125093$ 


\section{Nyasha Mboti and Keyan Tomaselli}

\section{Introduction}

Access to audiences is fundamental to any film industry. Control of film distribution 'routes', just like the ancient wars over salt, gold, spice, silk and slave trade routes, translates into ultimate power over what, how, where and why films are made. The control of film 'routes' is lucrative business, as illustrated by the power and wealth of the Hollywood majors and conglomerates. Distribution remains a decades-old constraint on the African film industry (Diawara 1992; Thackway 2003; Ukadike 1994). The control of film 'routes' has rarely been in the hands of African filmmakers or, for that matter, governments. In fact, only the Nigerian film industry has managed to crack the market (Haynes and Okome 2013).

Nigerians - maligned by almost everyone at first - have not only used the straightto-DVD model to make their films stand out prominently and distinctly from the crush of continental productions, but they have also successfully monetised them in the process. The problem of how to get films to audiences is at the heart of issues around the viability of the South African industry (see Mboti 2012; Shepperson and Tomaselli 2000; see also Treffrey-Goatley 2010). South Africa has the best infrastructure for production on the African continent, hosting more international productions and co-productions than anywhere else in Africa. Despite this, the industry remains a largely (and heavily) government-subsidised 'service provider' without an identifiable market for its products (see Tomaselli 2013) or a large enough corpus of 'own' stories to start or retain a distinct market. Despite the frequent affirmation that local is lekker (best), and that things must change, monologic duopoly-based models of distribution that cater to 'cinema-going' audiences not only remain, but are being entrenched. 'Trips-per-year' to conventional cinema theatres and box office returns remain the catch-all measure of the health of the film industry (see NFVF 2013).

The first part of the article argues that distribution/exhibition practices in the post-apartheid era perpetuate the inequities of the previous apartheid political economy. The second part examines the aims and potential of the ReaGilè concept to introduce a model of small-scale cultural enterprise in black townships that have long been deprived of access to screen culture and general leisure, recreational or digitally connected educational facilities. The problems of implementing ReaGilè as an employee-owned enterprise within the legislated framework of government development policy and social redress are discussed. The concept of ReaGilè is offered as an example of how difficult it is to introduce a new model of cultural enterprise in the shadow of entrenched large-scale business interests and state inertia, including obstruction.

We argue that the current duopoly system of distribution has not evolved much from its apartheid parent (see Tomaselli 1988). The current political economy of the local film industry lacks reflexivity, dialogue or movement due to its dependence 
on the paths of 'separate development' it inherited. This 'path dependence' involves strictly separating 'low-budget' from conventional high-budget features. Historyconscious theorists of South African film culture have noted that the economics of apartheid, particularly as built into the structure of the mining industry, gave fundamental impetus to the 'implantation' of film culture in South Africa (Masilela 1981). Hence:

Like practically everything else in South Africa, in which the economy is directly determinant, the evolution, the structure and the ideological complications of the South African cinema is to be explained in the context of the historical intractables and the social contradictions that were the outcome of the mining revolution ... it made possible the accumulation of capital from the surplus extracted from labour, particularly black labour; it transformed the demographic composition of the country, qualitatively and quantitatively shifting the population from the rural areas to the urban cities; it altered the country's cultural coordinates in immeasurable ways, specifically in relation to film culture, changed music halls into cinema halls, thus making way for the penetration of this new culture.

Thelma Gutsche (1972) points out, for instance, that beginning in 1919 the provision of 'special cinemas' for non-Europeans 'could not be contemplated for many years'. This was due to the non-Europeans' 'low wage level'. The use of wage as a justification for providing (or not providing) cinema for different groups of South Africans illustrates the problematic of the earnings-based political economy that remains dominant to this day. Superficially, this economy appears to be a neutral $<$ case of the play of 'pure' economics of the play of $>$ the free market, but is in fact a political, ideological and racially warped justification for a system not just for, as ReaGile's John Eschenburg avers, 'taking wealth from the poor and transferring it to the rich', but for preventing authentic dialogue and passage between having and nothaving, or what Tomaselli (1980: 7) calls the 'dialectic of insider versus outsider'. The monologic system that Gutsche saw at play in 1919 is still very much evident nearly a century later.

Film distribution and exhibition in South Africa are concentrated in the hands of a duopoly: the two companies, Ster Kinekor and NuMetro. United International Pictures (Universal) and Next Entertainment (20 ${ }^{\text {th }}$ Century Fox) complete the 'top four' on the basis that the main box office revenue earners for local cinemas are foreign films ${ }^{1}$ (NFVF 2013: 36). Fo some extent, indigenous film distributions and for-television commissioning distributors ${ }^{2}$ such as the South African Broadcasting Corporation (SABC), Mzansi, and DStv - which has been controversially buying content for its African Film Library pay-wall - make up the overall distributionscape. DVD sales, in stark contrast to Nigeria where they are a mainstay, are a receding blip on the South Africa distribution radar, mainly due to piracy, but also due to neglect by the industry. Interestingly, the neglect of the DVD market contradicts 


\section{Nyasha Mboti and Keyan Tomaselli}

recent research which suggests that DVDs are the number one preferred model for the majority of South Africans to access local movies (NFVF 2015a).

Online distribution platforms such as $\mathrm{VoD}$ (video on demand) are tentative newcomers hamstrung by negligible size, slow transmission and prohibitive cost of bandwidth, and data charges that are amongst the most expensive in the world. This has discouraged VoD applications, and Netflix and similar do not yet operate in South Africa, though currently there are signs of entry. Further, digital migration in this country lags considerably in comparison to other African countries. Though nearly everyone - including the poor in the cities - owns a cell phone, the latter use it as a phone rather than as a platform for watching movies or accessing the Internet. Cost and poverty are crucial impediments to the development of alternative digitaldriven media platforms using smaller, mobile screens. Government's control of telecommunications, under-investment and state-caused delays to digital migration all contribute to a lack of access to films by means other than cinemas and DVD rental stores.

Monopoly has been a feature of the local film industry since Isidore Schlesinger established African Film Productions in 1915 (see Gutsche 1972). One implication of this general for-profit monopoly is that a 'true' South African film industry, growing from the bottom up and with broad participation and buy-in, remains absent. Hundreds of micro-budget films made every year gather dust on shelves, unwanted and unnoticed by formal distributors or by influential central organisations such as the National Film and Video Foundation (NFVF). ${ }^{3}$ There is little will to grow a local film industry on the basis of low budgets, even if small-scale job creation and audience development are outcomes. The NFVF (2013: 6) defines distribution as the 'costs incurred to release and promote the finished film across cinema, DVD, $\mathrm{CD}$, video-on-demand, mobile, online and TV platforms' (emphasis added). ${ }^{4}$ This definition clearly marks distribution solely as a financial issue. That is, those better able to handle 'costs incurred' determine which films are distributed, where, when and how, and to whom. The NFVF largely supports the already capitalised.

A 'distribution blockage' (Rorvik 2010) constitutes the current state of affairs in South Africa. The 'proposed initiatives' or solutions offered by the NFVF to support the development of local film audiences and the growth and distribution of lowbudget films appear vague and insincere at best, and apartheid-dependent at worst:

- 'Development of a separate Film Incentive for low budget films targeting the broader demographic' (NFVF 2013: 39);

- 'Introduction of funding for alternative distribution mechanisms into the broader demographic' (NFVF 2013: 39, emphasis added).

The terms 'low budget' and 'low wage', are interchangeable. Big budget, on the other hand, seems to be an important way of creating, if not perpetuating, previous 
boundaries and centres of capital. The notion of developing 'a separate Film Incentive' reads, eerily, like a deodorised version of National Party-esque economics of 'separate development' and separate subsidies of 'films for blacks' (Tomaselli 1988: Chapter 3). Low-budget films are expected to develop, as it were, 'in their own areas', that is, in environments best suited to the 'lowness' of their own budgets. Where the ideology of apartheid previously 'dictated that there should be separate and distinct cinemas for the "different" public spheres' (Masilela 1981: 64; see also Fourie 1982), the NFVF and the Department of Trade and Industry (DTI) intend to separately fund 'low-budget films targeting the broader demographic' (NFVF 2013: 39). The 'broader demographic' is a euphemism for the unemployed, underemployed and employed black working class masses, who largely live in large towns, sometimes adjacent to (but more often separated at considerable distances from) places of employment in the cities.

The NFVF strategy aims to cement an economic activity of 'separate development', a policy for exclusively keeping wealth in the hands of the new political elite for as long as possible. In the context of a heavily government-subsidised film industry, and as we will show below, organs such as the NFVF and the DTI have exclusive state power to fund or not to fund. Their criteria for rejecting or accepting project proposals, a priori, define what is acceptable and objectionable within the conventional South African film industry.

The notion of introducing funding for alternative distribution mechanisms into the broader demographic suggests: 1) an approach based on the flawed logic that throwing (a lot of) money at a problem will make it go away; and 2) that alternative distribution mechanisms are meant to be introduced into black communities hypodermic needle-like, rather than by growing organically and heterogeneously from there. The lesson of the bottom-up organic success of the Nigerian film industry, for instance, remains a lesson lost in South Africa (see Brown and Mboti 2014). More importantly, it is through funding that the NFVF and the DTI can function as sentries who police and discipline boundaries in the local film industries through the 'accept/ reject' formula, and through rubber-stamping or delaying projects. As will become evident in this article, the NFVF's own initiatives, such as the 'Digital Screens', are rubber-stamped despite having clear design, organisational, marketing, managerial and social ecological flaws. While large development budgets are available, wellresearched projects such as ReaGilè are infinitely ignored, delayed, rejected or badly copied.

The NFVF (2013: 35) points out that South African cinemas do not deliver significant revenues for local films (other than those made in Afrikaans [with subtitles]), amongst other reasons, because of 1) the small cinema-going audience; 2) high exhibitor costs; and 3) short flighting windows. The reasons given, though specific, appear to lack both context and what Masilela (2000a: 63) would call a 


\section{Nyasha Mboti and Keyan Tomaselli}

'historical imagination'. The notion of 'cinema-going', for instance, is neither problematised nor deconstructed. 'Going' is both a structured symbolic performance and an economic ritual that expresses privilege within a for-profit, earnings-based capitalist political economy. The notion of 'going' distances product and consumer, and separates those who can 'go' from those who cannot. In South Africa, 'cinema' is placed at a remove from most people's lives. It does not grow amongst them but, rather, has to be 'gone' to. Historically, not everyone could 'go' or perform 'going'. Apartheid geography prevented this and is residual - few black townships have cinemas and the habit of cinema-going has never therefore developed in these locales. Rather, 'going' was a white, earnings-based practice and the cinemas were exclusively white places and spaces. Due to their 'low wage level', and distance from conventional theatre complexes, blacks could not participate in the earningsbased ritual of cinema-going.

The NFVF (2013: 35) study offers four reasons for the virtual non-existence of a black 'cinema-going' culture in South Africa:

- <Location:> during apartheid, cinemas were built only in white areas. Given that black individuals make up $79 \%$ of the entire South African population of 51.8 million (2011 Census), this has a significant impact on cinema revenues;

- Lack of access: cinemas are still predominantly located in (formerly) white areas. Low disposable income and high transport costs from townships to cinemas place these cinemas out of reach for the majority of the population;

- Price: tickets are unaffordable to the majority of the population with low disposable income;

- Lack of relevant content: all major exhibitors have agreements with international film studios. The current audience is more interested in Western content than local content, making up the bulk of box-office sales. Black audiences do not generally find this content culturally relevant and thus prefer to watch TV and purchase DVDs where content is colloquial. (TV is expensive, and low-budget movies can only be viewed via the expensive DStv subscription provider, which has numerous channels dedicated to films made by Africans.)

These four reasons are critical to our argument that blind-spots and 'shortage of intellectual capital' (Masilela 1981: 63) exist in the thinking of the state actors currently managing the industry. That is, all the given explanations for the absence of cinema-going publics are known, and have been authoritatively remarked on by Gutsche (1972), Masilela (1981) and Tomaselli (1988, 2013), among many others. Rather, it is the solutions that follow these explanations that continue to be flawed. For instance, the NFVF's (2013: 36) list of 'initiatives' to address these problems includes 1) cinemas with lower ticket prices, e.g. Ster Kinekor Junctions, where the 
price was lowered on certain days; 2) mobile broadcasting units that take the cinema to townships, e.g. Ekasi Movie Nights; 3) informal screenings in community halls and other township buildings; and 4) developing digital cinemas within townships (NFVF initiative).

None of these 'initiatives' seek to empower the communities into which they are parachuted. They are top-down approaches that hypodermically inject townships with a miraculous drug called 'cinema-going culture'. The NFVF's Audience Development Research Report (2010: 4) has as one of its major aims 'executing the NFVF mandate of creating a movie going culture among South Africans'. The report notes that 'the 16-20 age group represents potential movie goers', hence the NFVF saw itself as seizing the 'opportunity to inculcate appreciation of local films on them' (ibid, emphasis added). This take on industry processes arises from viewing film audiences as mere consumers of, and not active participants in and owners of, the whole local film industry value chain. It is never clear how the 'inculcation of appreciation' will be engineered, nor whether this is possible.

Furthermore, 'cinema-going' is complemented with 'cinema-bringing', where institutions such as the NFVF 'take the cinema to townships'. While 'cinemabringing' appears to be the reverse of 'cinema-going', it is really the continuation of apartheid-era mobile bioscopes, but this time in black-face. Not only is 'culture' still being brought into the townships instead of developing from there or being owned by the locals, but the power of decision (that is, funds and 'funding cycles') remains concentrated and centred in the hands of 'incentive-giving' (and 'threshold' lowering or increasing) institutions such as the NFVF and the DTI.

The sheer lack of cultural vision on the part of industry leaders and planners is clear in the contradictory policies and practices they adopt. For instance, the NFVF attempts to 'unclog' distribution bottlenecks by taking a select number of local films to Cannes. To illustrate, in 2015, the NFVF took 42 South African films to Cannes. The organisation 'promoted the 42 films at its booth at the festival through a booklet handed out to delegates and short trailers which were shown' (Bratt 2015). That is, Cannes is being touted as a 'new market' for local films. The NFVF even launched the Cannes South African Film Factory, a programme where four South African directors and four international directors collectively produce four short films 'that will have a greater likelihood of screening at the official Cannes Film Festival'. Beyond all this expensive grandstanding, however, the elephant in the room is the market back home, which is grossly overlooked and neglected due to the focus on festivals and the 'box office'. At any rate, such a focus contradicts the NFVF's own in-house research, with its latest report (2015a) proving that DVDs are by far the number one distribution model available to a vast majority of ordinary South Africans. Incidentally, cinema only comes a distant fourth. Local films' box office revenues dropped by 44 per cent from 2013 to 2014 (NFVF 2015b). CEO, Zama 


\section{Nyasha Mboti and Keyan Tomaselli}

Mkhosi, ironically stated that, when planning its recent Cannes strategy, the NFVF drew on the results of the latest survey it conducted on South African audiences' perceptions of locally produced films. Some of the findings were 'that most South Africans find no fault with locally produced films but would pick watching a DVD at home than going to watch a movie on the big screen'. One wonders what taking 42 movies to Cannes has to do with improving locals' access to local movie fare.

Lately, institutions such as the NFVF have been making seemingly right-sounding noises about distribution. The current $\mathrm{CEO}$, for instance, is on record as saying:

We will be focusing on unlocking the bottlenecks on the distribution front and open up new markets for SA content. The focus has always been put on production and improving the quality of them, but now we will focus on solutions to distribution which are moving with the times.

The problem, as usual, is one of sincerity. Can the bureaucrats walk the talk? As long as initiatives such as ReaGile continue to be systematically ignored, it seems that the answer is negative.

How can the 'distribution blockage' be genuinely unblocked? What other issues lie in the way of the film 'route'? How can the ghost of 'separate development' be exorcised from South Africa's political economy? This article applies the case of ReaGile to an interrogation of these and other questions. Part of the answer, which is crucial to addressing all the other questions, is to examine ReaGile as a specific example of a 'development node'.

\section{ReaGilè: unblocking distribution}

ReaGilè (pronounced 'Ree-e-gee-le') is a Southern Sotho word meaning 'We have built'. This name was adopted for a project inaugurated in Gauteng in 2009 to build and situate pre-fabricated, self-contained, education and entertainment complexes on $400 \mathrm{~m}^{2}$ sites at public open spaces across South Africa. The complex consists of a 60 -seat cinema theatre, 30 -seat computer and Internet centre, community care and a community policing centre. ReaGilès were intended to service historically underserviced townships and peri-urban areas with catchments of 30000 within walking distance of cinemas.

Why cinema in the townships? The ReaGile vision is directed at disrupting the modernisation paradigm (Mboti 2012) and alleviating poverty through initiating authentic local development projects unencumbered by exploitive profitmaking, sectional ideological interests, or the corruption that underpins policy implementation. ReaGilè's objective was to help create jobs, especially amongst the youth, women and the disabled. Based on the philosophy of ubuntu, and applying a dialogic strategic partnership cooperative model, each ReaGilè co-op was intended to provide auditorium and computer education facilities to black townships, to be 
owned and managed by 27 local community members. The cooperatives would offer medical aid and an equitable share of distributable profits to each member, and levy affordable prices. They would offer sport, edutainment, community news and adverts on five outdoor screens. Start-up capital was to be financed through government, other grants and/or term loans, and eventually advertising would contribute the major income to the ReaGilè that operated like a franchise, but without charging franchise fees or extracting income from box office receipts, though distributors were projected to earn R350 million annually.

ReaGile's philosophy 'to rebuild' South African publics and communities that had been fragmented by apartheid. Basically, locally-led and locally-owned social and economic development is a function of co-op performance. That is, the co-ops are the real owners - as opposed to employees - of ReaGilè. The ReaGilès were to be run as local businesses, with local owners. In short, the complexes intended to function as local 'development nodes'.

A development node is a point where human and economic resources and activities are concentrated and from which they multiply and spread for the benefit of a given community. Nodes facilitate sustainable economic and community development by bringing together people, resources, skills, land uses and infrastructure within close proximity. The notion of a development node is crucial in that it re-frames the notion of a 'distribution blockade' in developmental terms. Rea Gilè is a developmental node in the sense that it offers a place or structure from which an active local development network is meant to spread, and through which traditional film industry value chains are altered. ReaGilè was intended to add value through 'multiplier effects' such as job creation, community policing and prompting a cinema-going culture. As Tomaselli (2013: 6) argues, 'without local audiences in sufficient numbers, the film industry will, with a few exceptions, remain subsidy-dependent and driven, export-based', rather than being locally viable.

As a one-of-a-kind 'film service', the ReaGilè concept offers opportunities for the alternative distribution of micro-budget local films as well as imports. Hence, it has the potential to alter the traditional film industry value chain which is based on a distribution monopoly exercised by Ster Kinekor and NuMetro - and, to some extent DStv, SABC and eTV - while at the same calling into question the enormous formulaic power concentrated in the hands of fund-heavy state organs, such as the NFVF and the DTI.

\section{Building ReaGilè}

The equipment and technology for building a ReaGilè cinema unit is all sourced locally, but mostly manufactured overseas. Building a ReaGilè cinema takes two weeks with a workforce of ten. A full ReaGilè unit (cinema, Internet centre, aid centre and policing centre) can be built in six to eight weeks. The life-span of a ReaGilè unit 


\section{Nyasha Mboti and Keyan Tomaselli}

is permanent, since every facet of the technology and equipment is replaceable. Due to the unique design of the complex, there is little to no damage during moving. The co-ops, along with the municipality and iHs (the project's holding company), decide where a ReaGile unit is placed or moved to.

\section{Political economies of accept/reject}

In the post-apartheid dispensation, local governments as well as government departments and agencies are instrumental in the success (and failure) of local projects such as ReaGile. There are 278 municipalities in South Africa, comprising eight metropolitan, 44 district and 226 local municipalities (South Africa Yearbook 2011/2012). The stated purpose of local governments is to grow local economies, and provide infrastructure and services. This focus suggests that common ground exists between the aims of ReaGile and those of local governments. That is, local

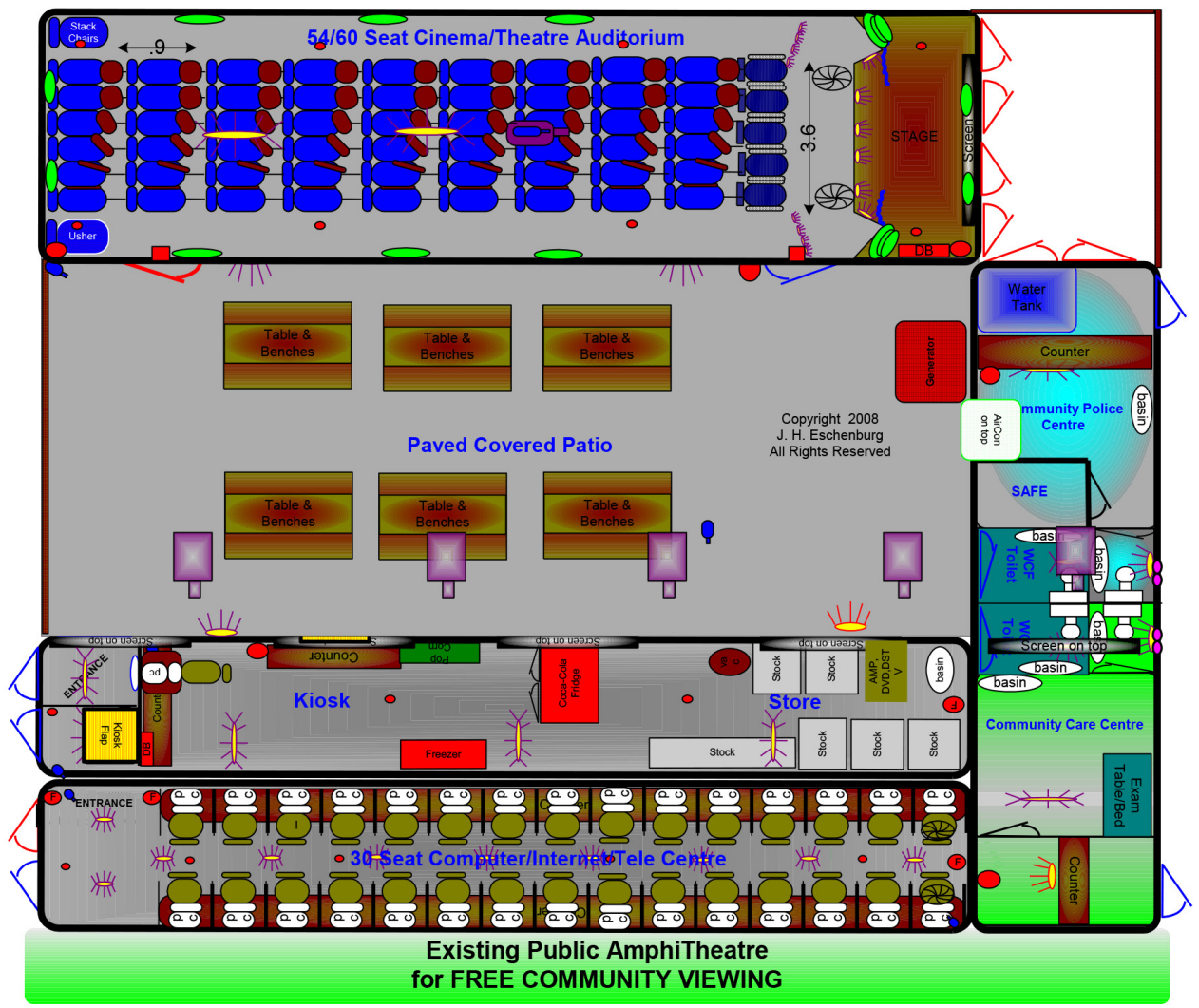

Figure 1: ReaGilè complex floor plan 


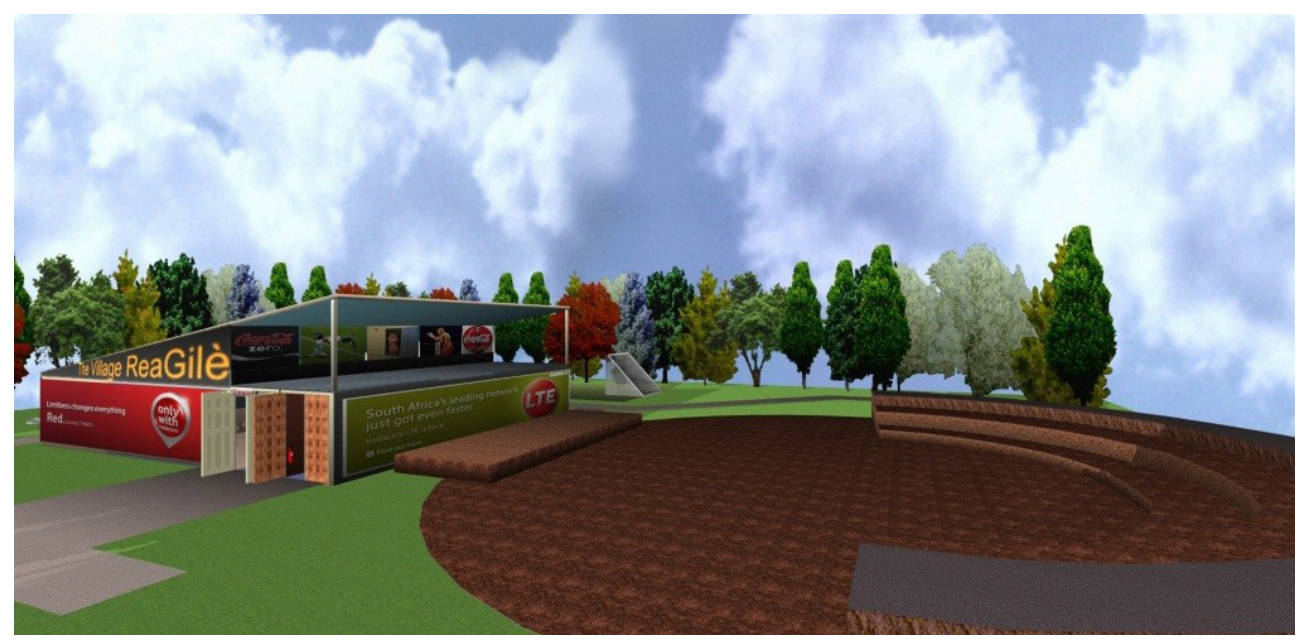

Figure 2: CG model of ReaGilè complex with amphitheatre

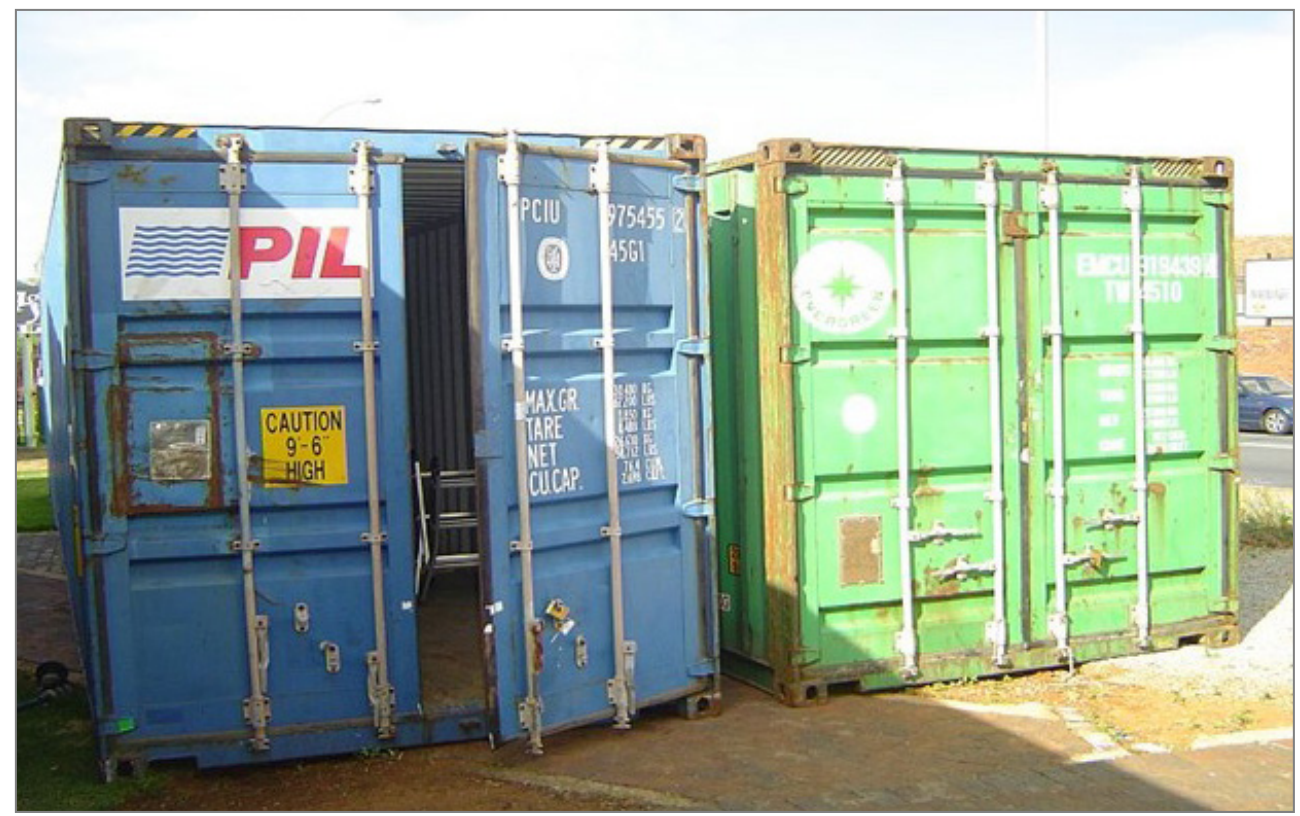

Figure 3: The ReaGilè complex is housed in unique, prefabricated, container-based structures. The cost of building material is much reduced but without actually compromising on the quality of the final structure. The cost-effective nature of ReaGilès ensures that they are not another wasteful method of handling tax-payer rands. ReaGilè are also an unsurpassed recycling idea. Photo: Darren Eschenburg® 

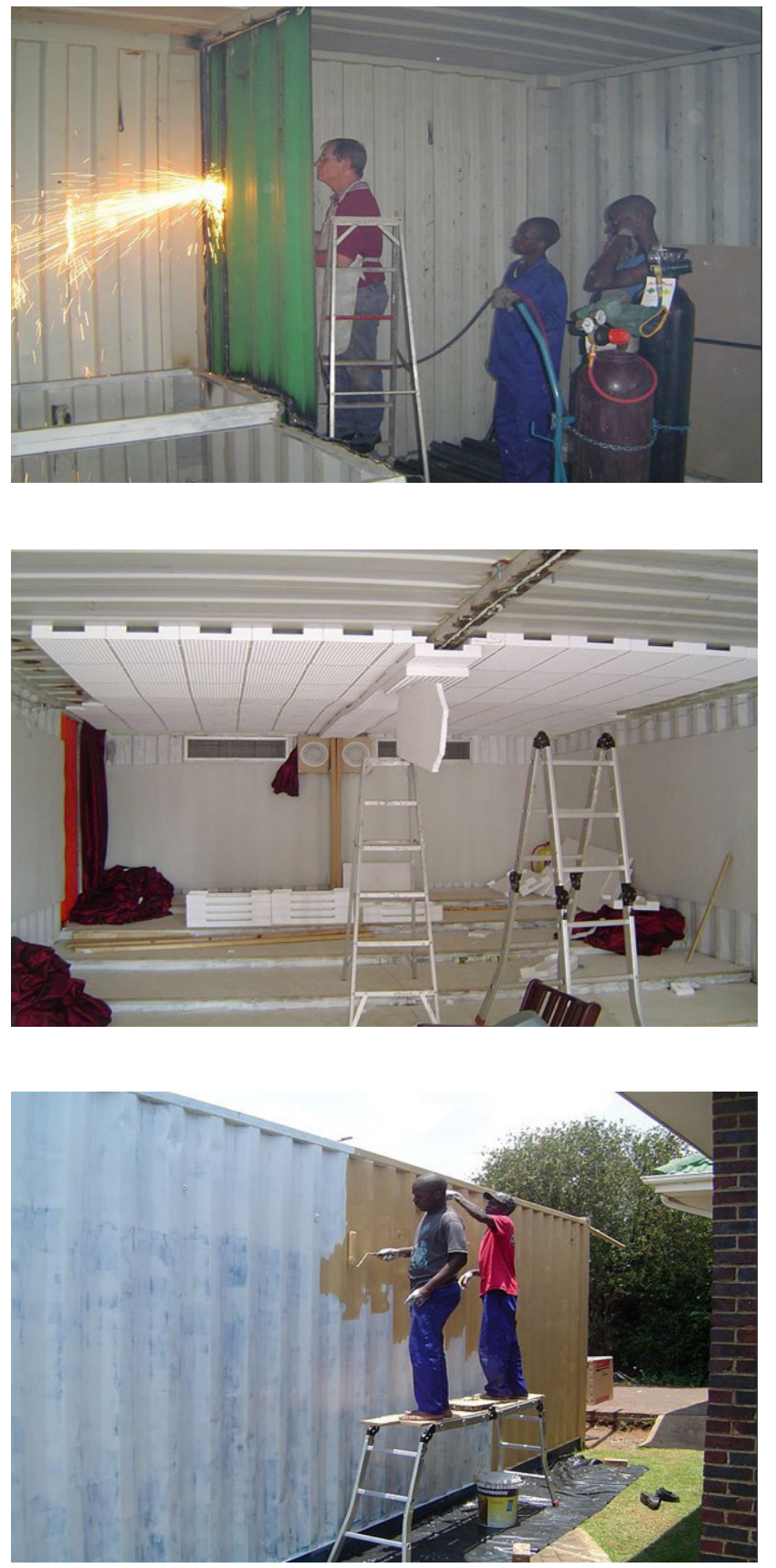

Figure 4: Construction begins with panels welded together using basic welding techniques and innovative engineering ideas. Also, at the construction stage, jobs are created in the community while there is also skills transference. Photo: Darren Eschenburg $\Subset$

Figure 5: Constructing the interior of a ReaGilè, including walls, ceiling and floor tiles. Insulation, padding, soundproofing, wiring and other internal work is carried out according to the best interior industrial design specifications available at affordable, accessible cost. Like in any conventional cinema, there are no windows. Rather, the interior is fully air-conditioned. Photo: Darren Eschenburg $@$

Figure 6: Painting the exterior. The container is a very mobile piece of technology and can easily be transported from place to place. Photo: Darren Eschenburg ( 


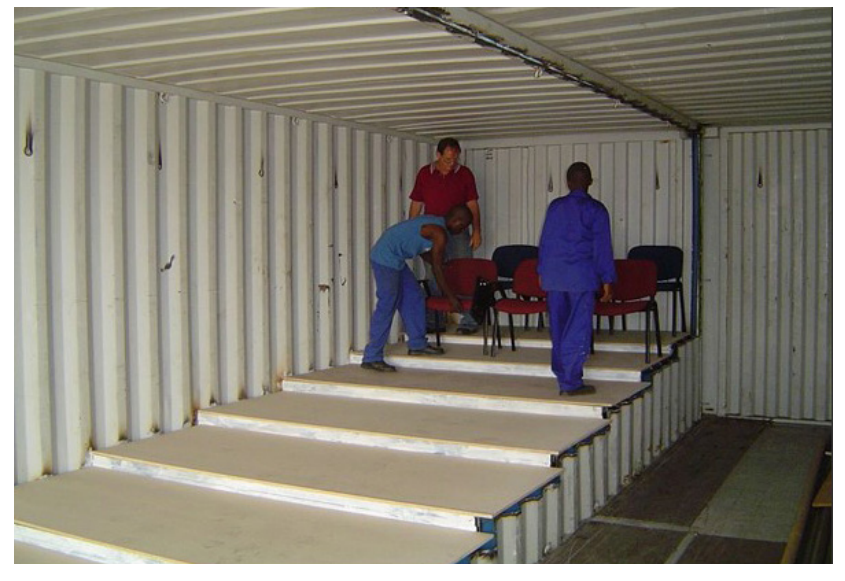

Figure 7: Setting up and testing the internal structure. Photo: Darren Eschenburg $`$

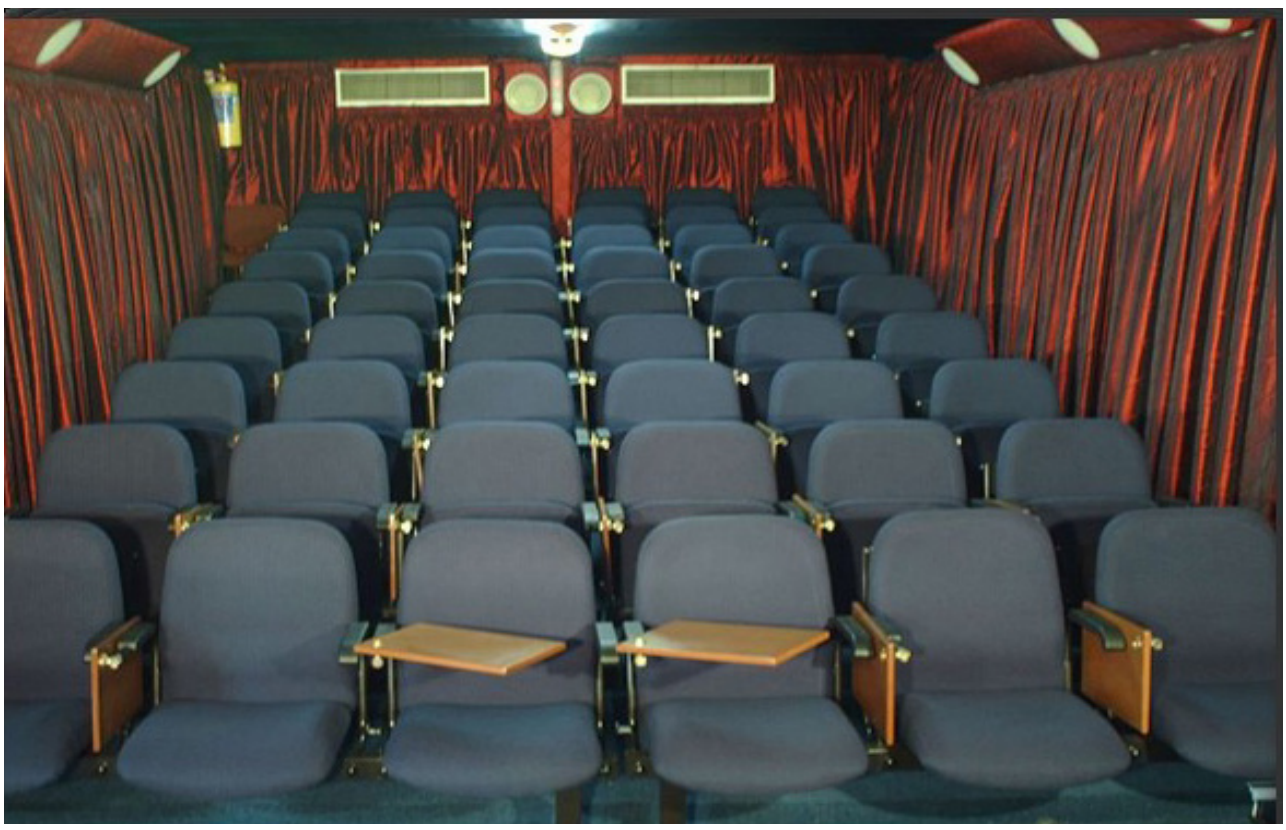

Figure 7: Inside a ReaGilè cinema - finished interior. The seats afford comfortable seating while also having foldable panels that instantly turn the seat into a desk-and-chair for workshops, seminars and other uses. Because of the insulation, the interior is noiseless. Cool and warm air can be regulated via environmentally-friendly air-conditioning. Cinemas like this one will screen, for instance, seven hours of educational material and nine hours of feature films to paying clients, with enough 'spectrum' also available for short films and local-language films. Photo: Darren Eschenburg $₫$ 


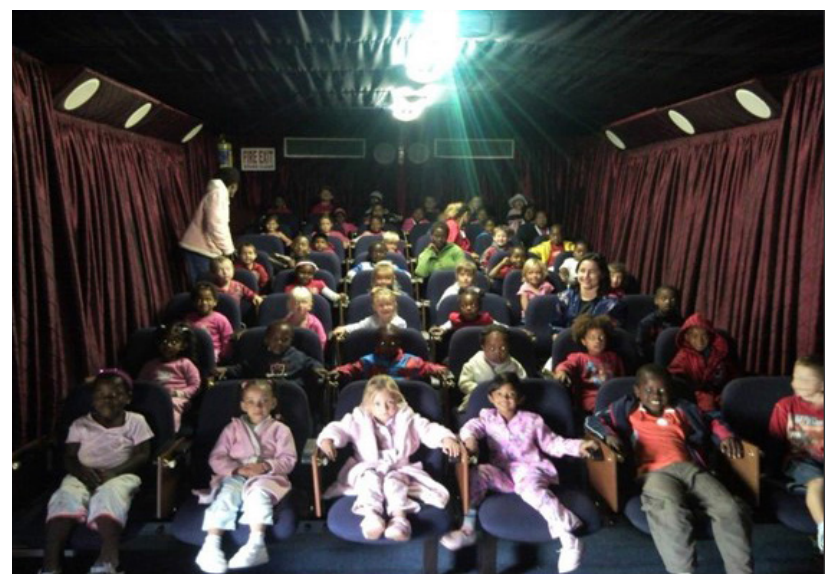

Figure 8: The 60-seat interior of a ReaGilè is surprisingly spacious, owing to the intelligent interior design. The lighting is plentiful for practical activities, but can be turned off at a flick of a switch for an immediate, dark theatre experience. The lights are energy-saving bulbs. At the sides and back is the 9.2 ch surround sound system. Also at the back is the airconditioning. Photo: Darren Eschenburg $\odot$

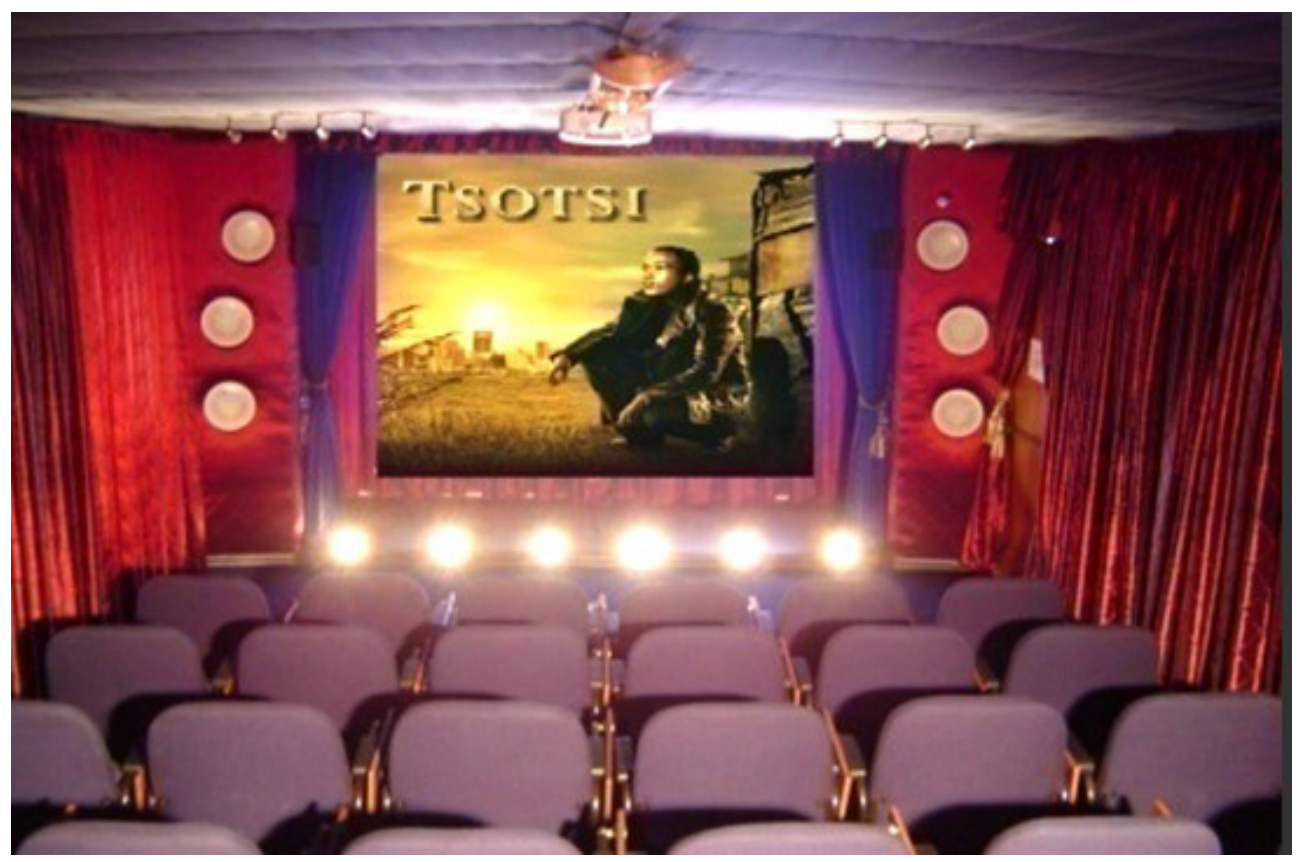

Figure 9: An interior view of the indoor theatre screen and auditorium. Shown here is a mini theatre stage for live-show performances by performing arts groups as well as a video-based education centre, providing life skills and availing training to the local community. This $54 / 60-$ seat cinema, within easy walking distance, and showing local-language and international films, has the potential to alter the traditional value chain of the South African film industry. That is, for young South African emerging filmmakers, this exhibition site has the potential to solve current problems of distribution. At the very least, it has the potential to create a huge demand for local films. Photo: Darren Eschenburg® 


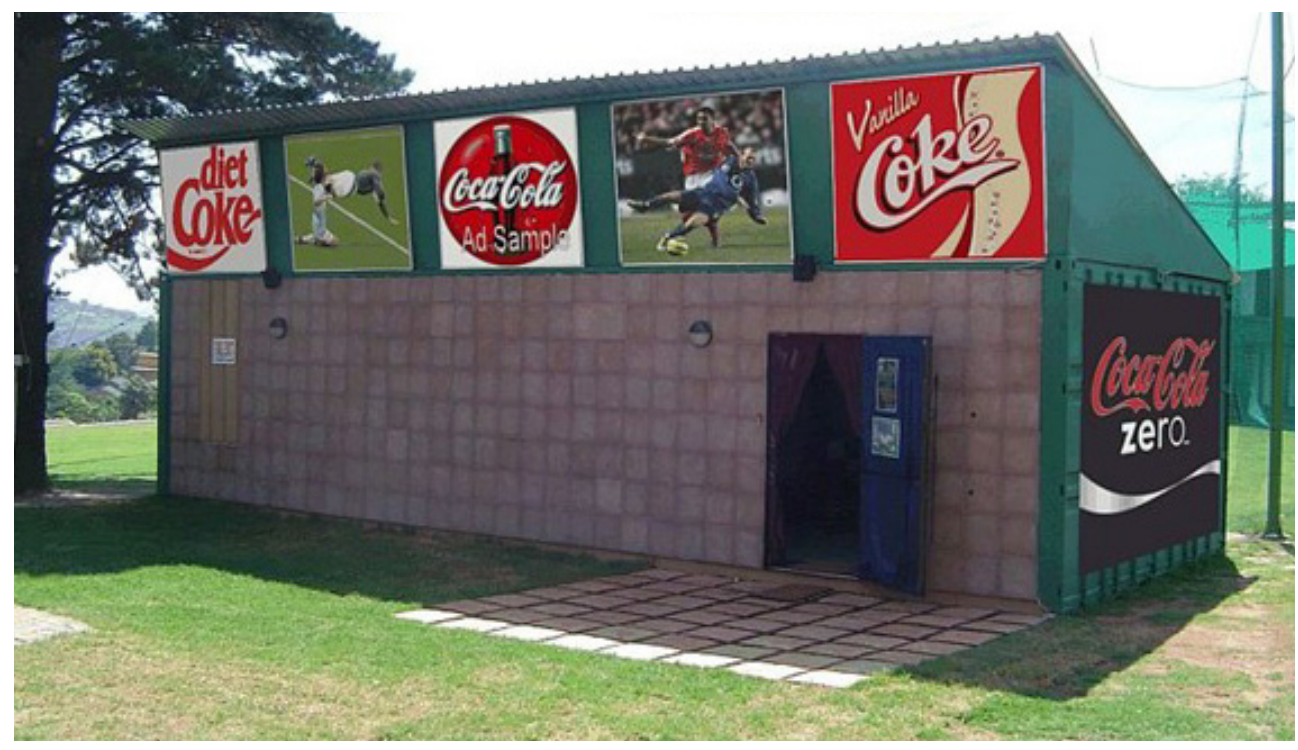

Figures 10: ReaGilè cinema as seen from the outside, showing outdoor screens. A total of five 2.7 outdoor screens, overlooking a public viewing area/park run from 18:00-24:00. The outside is meant to be a free public viewing area, showing sport, community news, local township-produced short films, advertising, information and public health awareness, etc. It also doubles up as a community edutainment facility for the display of a range of local township-produced media, with a bias towards productions by community youths. Photo: Darren Eschenburg $\complement$

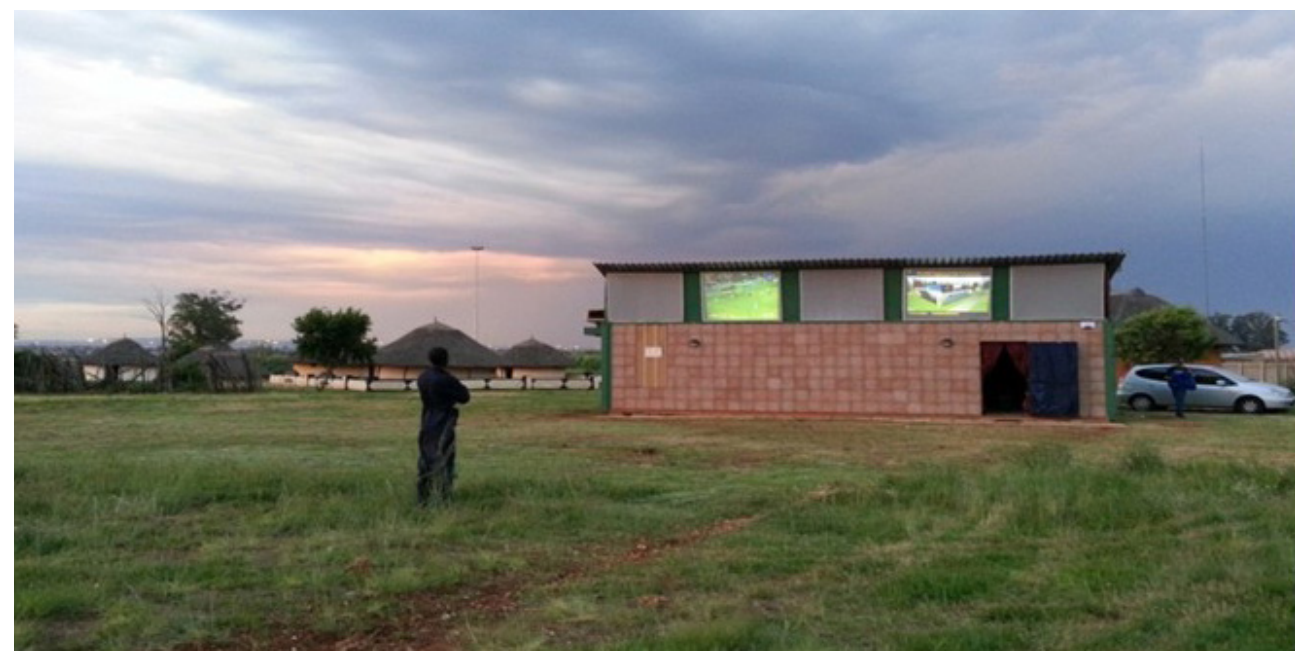

Figure 11: The first complex at Katlehong, Gauteng, January 2013. Photo: John Eschenburg( 


\section{Nyasha Mboti and Keyan Tomaselli}

government buy-in is crucial. There is need, for instance, to negotiate for permission to place ReaGilès on municipal land such as parks, school grounds, church sites and, crucially, for funding for roll-out. To this end, ReaGilè representatives - over a period of five years - met with government department representatives, city managers, mayors and mayoral representatives from Johannesburg, Ekurhuleni, Mogale (Krugersdorp/Randfontein), Durban, Matlosana (Klerksdorp) and others.

Incidentally, South Africa's national government, through the relevant ministries, departments and agencies, has for several years kept up the mantra about government-led job creation. At the same time, however, potentially self-financing and sustainable job-creation innovations such as ReaGilè have been continuously and systematically delayed, stalled and choked out of existence. Between 2009 and 2014, over 50 meetings were held between representatives of ReaGilè and the DTI (each lasted, on average, two hours) $)^{5}$. The DTI also carried out several site inspections and verbally expressed interest in funding the entire roll-out of 1200 units. Despite these meetings, and notwithstanding the DTI's apparent interest, concrete support never materialised and no formal agreements were signed, though Minister Paul Mashatile, of the Deprent arts and Culture, provided a written endorsement for the project. According to ReaGile's John Eschenburg, the common and most consistent responses from municipalities were 'I'll get back to you', 'I will revert to you' and 'I will call you back'.

Furthermore, 21 meetings were held with the NFVF, whose 'Long-Term Strategy' or VISION 2025 is about 'Taking Cinema to the Citizens'. ${ }^{6}$ The NFVF pointed out that it had a purse of up to R10 million to place cinemas in townships and rural areas. ${ }^{7}$ After initially showing strong interest in the concept, the agency went quiet. In 2012, however, the NFVF started inviting bids for the placing of digital cinemas in townships, to be managed by the Foundation itself. ${ }^{8}$ The bid, subtitled 'Appointment of a Service Provider for the Establishment of Digital Screen Facilities in Underserviced Areas' is significant for the way in which its 'Phase 2' of the 'Evaluation Criteria and Processes to be Used' effectively and arbitrarily excludes most South Africans:

Phase 2 - Technical/functional requirements: This evaluation was based on the responses using the functional requirements i.e. previous experience, expertise and/ or financial strength. The threshold values set for the qualification of bid is $60 / 100$ for weight and all the bidders who score below this score will be eliminated. To be responsive the bidder must score $60 \%$ OR more on functionality.

By giving only ten per cent to South Africans with ' 5 years and below' of 'Experience in South African film exhibition landscape', the NFVF bid terms exclude emerging players while skewing the screenscape to suit Ster Kinekor and NuMetro. A 'high level of knowledge of the business world', which established players are also likely 
Table 1: The National Film and Video Foundation bid terms

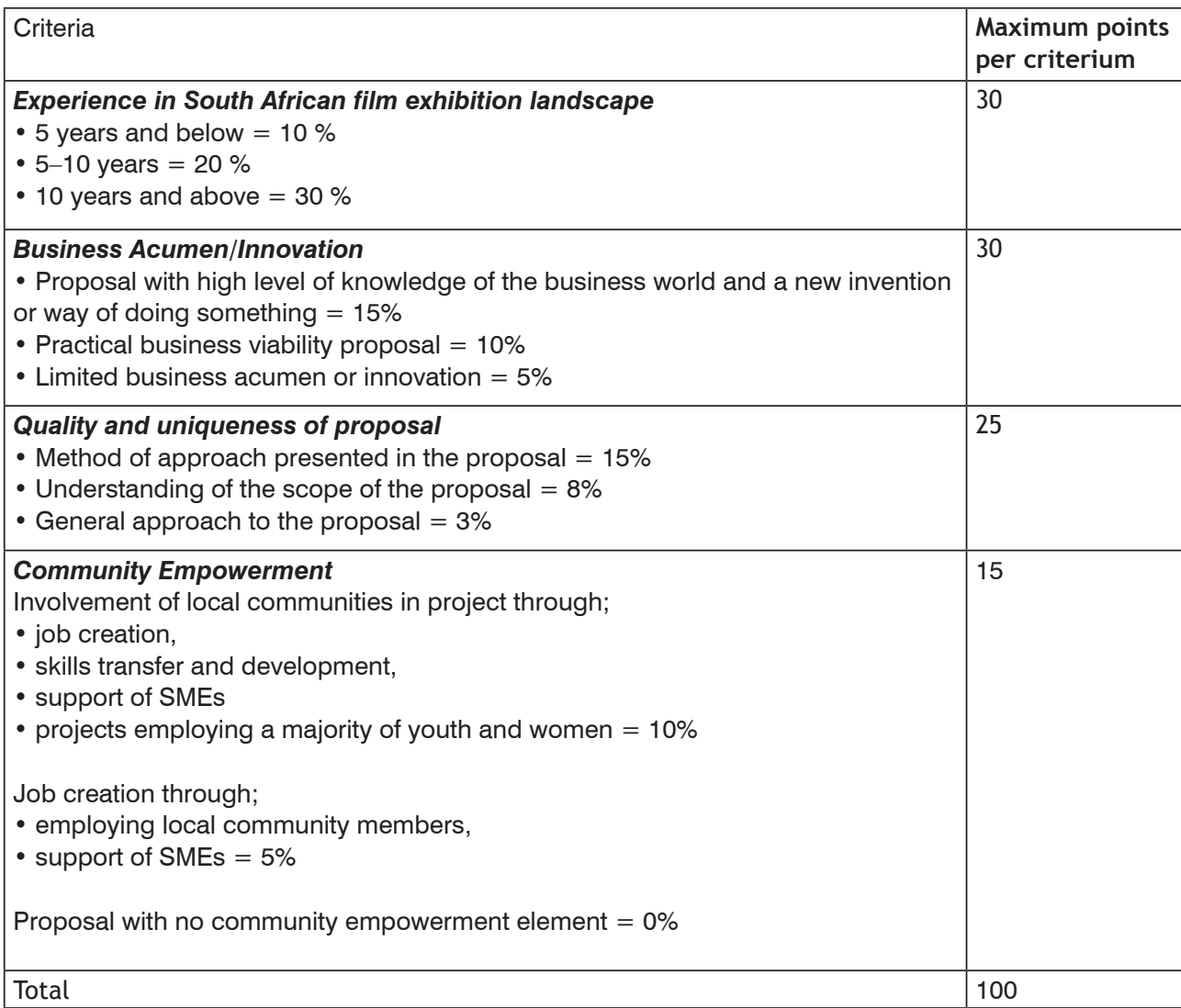

to have, also receives 15 per cent. 'Job creation' - one of the centrepieces of an innovation such as ReaGilè - only gets a five per cent score. The idea to establish digital screens itself does not seem to have employment creation in mind, since the structures will be owned by the NFVF and are likely to employ only a guard/gateman and a technician. In the end, it is highly unlikely - on the basis of NFVF's elitist scoring method - that non-traditional and emerging projects will score more than 40 per cent. Finally, it is arguable that the NFVF has, to some extent, mimicked $<$ duplicated? $>$ ReaGile's intellectual property.

ReaGilè representatives have had multiple meetings with other government agencies, such as the Industrial development Corporation (IDC), the National Empowerment Fund (NEF), Arts \& Culture, the National Youth Development Agency (NYDA) and the Gauteng Film Commission (GFC). The NEF, for instance, agreed to favourably consider any ReaGilè co-op which received funding from 


\section{Nyasha Mboti and Keyan Tomaselli}

the DTI Co-op Incentive Scheme (CIS) directorate. The IDC, on the other hand, agreed that the project was innovative and worth funding, but did not have a funding mechanism for cinemas in townships and rural areas at the time. A mechanism was, however, created, but on applying for the funding, ReaGile was told that the IDC was preoccupied with other role players and would revert back after concluding negotiations with those role players. Hundreds of hours of 'talk' become a systematic delaying and hamstringing mechanism. Operationalising the project was constantly stalled by local government inefficiencies, intransigent personnel, and, at local level, corruption. ${ }^{9}$

\section{Path dependency ${ }^{10}$}

Despite the sophistication of the ReaGilè business plan, available private investment and distributor support, the lack of traction within all levels of the state might be explained by the concept of path dependency (see North 2010). Path dependency occurs when a successor state or organisation adopts similar strategies to the one it has replaced. As a result, the new state, having failed in many respects to provide due leadership, now, like the latter-day experience of the apartheid state, increasingly finds itself cautioned, questioned and replaced by NGOs and civil society sectors.

The state, it appears, wants to be both referee and player, without the capacity of doing either properly, let alone simultaneously. The state is suspicious of sectors acting as an internal-opposition/collaborator/implementer (the Treatment Action Campaign is a prime example in the field of health). The NGO-sector is pereeived to threaten aspeets of the post-apartheid hegemony as government has no effective strategy - other than cooptation, repression and patronage - to manage the 30 million impoverished and increasingly restive citizens largely held external to the benefits accruing to the new ruling class alliance (the African National Congress [ANC], the Congress of South African Trade Unions [Cosatu] and the South African Communist Party [SACP]). The NGO sector is seen to be working amongst the 30 million, often competing with the state (e.g., ReaGilè proposed 1200 cinemas, while the NFVF's proposed 150 township 'screens').

The path dependency inherited by the ANC from both the National Party on the one hand, and eommunism on the other, where many in senior state pesitions respectively learned their economies and polities, is that the economy is a fixed-size cake, to be cut up with the largest slices going to the new and old elites (see Mbeki 2009; Terreblanche 2012). The economy is not understood by this fraction-as a set of production factors, financial relations and organisational strategies that can grow the gross national product (GNP) cake (see Porter 1990) and into which many of the excluded can through the facilitation of small-scale self-sustaining ventures, as it is being offered by ReaGilè, amongst thousands of others (Tomaselli 
2013). Basically, and ironically, more resources for the poor (as it is being suggested by ReaGilè) are reductively seen to translate into fewer resources for the rich.

The strategy of patronage includes the South African president's chimerical promise of six million jobs, on which the state cannot conceivably deliver. But the state is unwilling to squander the ideological hold it has on its increasingly angry rank-and-file supporters, when ventures like ReaGilè claim to be able to assist it to deliver on job promises. ReaGilè's challenge that it can stimulate 37500 jobs on full roll-out, given appropriate public-private partnerships, is possibly considered something of a living threat to the state's (ideological) claim to be the sole repository of job creation. By rhetorically holding this position, the state thus aims to retain voter support (even if this citizenry engages in fiolent aets due to poor service delivery) from those who will never get jobs under the current dispensation, but whose loyalty is secured by no fewer than 16 million state social grants. A debt bondage economy enstres ANC voter support.

Ventures such as ReaGilè, read through economist Moeletsi Mbeki's (2009) analytical prism, are incorrectly assumed to host the consumptive economy rather than being part of a productive economy. Indicative of such consumption, the state would rather own these kinds of capital-accumulating ventures than work with them in facilitating a productive sector. Hence the sometimes opportunistic Black Economic Empowerment (BEE) interest in wanting shares in ReaGilè, rather than the BEE constituency being concerned with how ReaGilè will empower the poor.

ReaGilè transgresses two received path dependencies inherited by the ANC from the National Party's sectionalist national-socialist apartheid economy. The private sector produces the wealth that is appropriated by the public sector and many of the BEE companies that consume and squander it (Mbeki 2007). Projects such as Rea Gilè are creators of local wealth, and do not collaborate with the state in opportunistically consuming it (e.g., via bribery, 'tenderpreneurship', corruption, hand-outs, expedient share allocations, etc.). If the path dependency is based on patronage and economic bondage, the immediate benefit of ReaGilè to the state-dependent elite bureaucracy is unclear to this constituency, notwithstanding the promise of 37500 jobs and those that the ReaGilè complexes will generate via multiplier effects.

\section{Beyond the path dependencies: small-mall-plexes}

The ReaGilè project is the locally owned equivalent of a corporate-owned urban mall. ReaGilè is a small-mall-plex attracting users/consumers centred on a group of ancillary services (community policing, primary health care clinic, refreshment kiosk, educational use, etc.). As such, ReaGilè to introduce a new kind of low-volume community-centred commerce/public service that would be of direct benefit to localised since what is spent, and the services to be delivered, largely remain within the catchment community. The smallplex is the low-income 


\section{Nyasha Mboti and Keyan Tomaselli}

and informal settlement equivalent of a large city mall, where suburbanites get their entertainment and exercise in safe, clean, air-conditioned and policed environments.

Urban renewal is linked to entrepreneurship/empowerment, which further links to job creation, which finally results in poverty alleviation and potential upward class mobility. The economic cake thus gets bigger - it is not a fixed size, as some socialists are often accused of assuming. Some among the 30 million poor will begin to identify the benefits offered by such small-seale ventures. They will-become more because each of the 27 employees of each ReaGilè complex will now be better able to support his/her own experience in setting up the first mini-cinema in a run-down publicly funded cultural village in Katlehong, near Johannesburg in April 2009, is instructive. Forming the cooperative to own and manage the complex proved difficult in that recruitment assumptions had to be re-assessed. Many of those applying to join the cooperative, in fact, were looking for paid 'jobs' rather than entrepreneurial opportunities that they could grow from scratch. They were not interested in career paths, but in easy money.

Where big urban multiplexes are middle class-based operations, indicative of upward mobility, smallplexes would the unemployed and working class, facilitating the emergence of nascent urban cores around which basie modernisation impulses within peripheral zones can grow. These could, over time, be incrementally incorporated into the national space economy and facilitate job creation centred on, and spinning off, the smallplexes. In time such complexes will generate sufficient turnover for VAT-rating purposes, and perhaps also income tax with regard to the five owners of each facility once tax thresholds have been reached. Smallplexes can be used to screen local films made by low-budget filmmakers who are unable to secure mass distribution through the normal channels. This might enable them to earn a living from their production work and to develop a sustainable production career.

\section{A post-colonial conundrum}

Our argument here stems from Masilela's (2000a) framing of Thelma Gutsche's (1972) historical project. That project was of a modernist nature, examining how the early film industry developed against the background of colonialism and early $20^{\text {th }}$-century postcolonialism (i.e., Afrikaner resistance against English domination, and African resistance against both Afrikaner and English domination) (see Tomaselli 2008). If film practice, according to Gutsche, is one of the quintessential forms of modernity, then as Masilela argues, 'national' cinema could not emerge under apartheid. A national cinema is unattainable under the present conditions, while the unemployed and underemployed black majority remains economically disenfranchised, geographically remote, spatially segregated and class differentiated (qualifying only for 'separate budget' support, dependency fostered by cinema- 
bringing, and consumerism fostered by cinema-going to complexes owned by big capital). The NFVF's top-down exclusion of local stakeholders from ownership of cinemas stands in stark contrast to the inclusive, bottom-up ReaGilè model. The question of the route selected in a class-based one.

The path dependencies influencing the NFVF are based on the idea of routes of old, the ReaGilè path breaks with received assumptions, and opens up new distribution and exhibition and even production routes. Where the former top-down approach is based on trade, aid and consumption, the latter is developmental, generative and selfsustaining. The former holds onto power, the latter cedes it.

\section{Postscript}

The visionary who devised and tried to implement ReaGilè, John Eschenburg, was killed in a traffic accident in April 2014, near the single working ReaGilè cinema in Katlehong, just as the project was gaining traction in the host municipality. With him died ReaGilè. This article is thus dedicated to John.

\section{Notes}

1 Of the 74 films released in South African theatres from April 29 to August 31 in 2011, for instance, 73 per cent originated from the US either as a US film or a US co-produced film (NFVF box office report May - Aug 2011).

2 The NFVF (2013: 37) study reports that license sales from broadcasters are 'often a South African film's biggest revenue stream'.

3 The NFVF is an agency of the Department of Arts and Culture, 'a statutory body mandated by parliament to spearhead the development of the South African film and video industry'. See http://nfvf.co.za/about-the-nfvf

4 The NFVF's economic baseline study $(2013: 4,39)$ identifies seven 'focal areas' that it argues will guarantee sustainability and commercial viability 'in the long-term'. Two such areas are 1) 'supporting the development of local film audiences and associated distribution methods; and 2) supporting the growth and distribution of low budget films'. Indeed, five of the seven 'focal areas' relate directly to distribution, hence revealing its relevance.

5 Both authors participated in various meetings during 2013 as The Centre for Communication, Media and Society had offered pro bono research services to the project.

6 NFVF 'Policy \& Research', http://nfvf.co.za/policy-research (accessed 14 June 2013).

7 The agreements reached with the NFVF were to Build and install a 50-seat, 11.2 channel Sensurround HD ReaGile cinema in the NFVF offices; Install a 'Full Surround Sound Cinema with HD DSTV and Projector and Screen' in the 280-seat Ekhaya Multi Arts Centre in Kwa-Mashu, Durban, prior to the 2010 FIFA World Cup; Also install a 'Full Surround Sound Cinema with HD DSTV and Projector and Screen' in East London and in Cape Town; Do all of the above three cinemas for under R500 000 in total, and complete all three in less than one week, even though equipment was extremely scarce in the week the 


\section{Nyasha Mboti and Keyan Tomaselli}

World Cup started. Only the first agreement was completed, i.e., ReaGile installed the NFVF and Kwa-Mashu cinemas before the 2010 FIFA World Cup.

8 http://www.filmcontact.com/africa/south-africa/invitation-bid-digital-screens

9 ReaGilè has, in a few cases, been asked to pay a bribe and to cede ten per cent shares so that it could place ten units in a municipality and surrounding townships. Such corrupt propositions have been made by officials at the level of mayor, city manager and LED manager.

10 Tom O'Regan and Eric Louw helped us to conceptualise and write this section.

\section{References}

Bratt, M. 2015, June 15. Mission NFVF: unclogging distribution bottlenecks, opening new markets. http://themediaonline.co.za/2015/06/mission-nfvf-unclogging-distributionbottlenecks-opening-new-markets/ (accessed $\varsigma_{\curlywedge}>$ ).

Brown, M. and N. Mboti. 2014. Nollywood's 'unknowns': an introduction. Journal of African Cinemas 6(1): 3-9.

Diawara, M. 1992. African cinema: politics and culture. Bloomington, IN: Indiana University Press.

Fourie, P. 1982. A structural-functionalist model for the formulation of a SA film policy, Part 1. Communicatio 8(1): 2-9.

Gutsche, T. 1972. The history and social significance of motion pictures in South Africa, 1895-1940. Cape Town: Howard Timmins.

Head, B. 1975. A question of power. London: Penguin.

Masilela, N. 1981. Issues in the South African cinema. http://pzacad.pitzer.edu/NAM/ general/essays/cinemasouth.pdf (accessed 3 April 2014).

Masilela, N. 2000a. Thelma Gutsche: a great South African film scholar. Critical Arts 14(2): 49-70.

Masilela, N. 2000b. Is there a South African national cinema? In Lab jahrbuch 2000 für künste und apparate, ed. T. Hensel, H.U. Reck and S. Zielinski, 232-238. K $\square \operatorname{ln:}$ Verlag der Buchhandlung.

Masilela, N. 2003. The new African movement and the beginnings of film culture in South Africa. In To change reels: film and film culture in South Africa, ed. I. Masilela, <pages> . Detroit: Wayne State University Press.

Mbeki, M. 2009. Architects of poverty: why African capitalism needs changing. Johannesburg: Picador Africa.

Mboti, N. 2012. ReaGilè in South Africa's townships: tracing the design and development of a 'small' idea for life-size community upliftment. Commonwealth Youth and Development 10(1): 12-32.

NFVF. 2010. Audience Development Research Report. http://nfvf.co.za/sites/default/files/ docs/audience_development_research_report.pdf (accessed $\left.<_{\lambda}>\right)$.

NFVF. 2013. South African film industry economic baseline study. http://www.dac.gov.za/ notices/2013/NFVF\%20South\%20African $\% 20$ Film $\% 20$ Industry $\% 20$ Economic $\% 20$ Baseline\%20Study\%20April\%202013.pdf (accessed $<$ >). 
NFVF Audience Research Project. 2015a. http://nfvf.co.za/home/22/files/Reports/FINAL NFVF\%20ARP-QuantReport_10042015cc.pdf (accessed $<>$ ).

NFVF Box Office Report. 2015b.http://nfvf.co.za/home/22/files/Research\%20reports/ Box\%20Office\%20Report\%20Feb\%202015.pdf (accessed $<$ P).

North, D.C. 1990a. Institutions, institutional change and economic performance. New York: Cambridge University Press.

Porter, M. 1990. The competitive advantage of nations. $<_{\mathbf{P}}$ : The Free Press.

Rorvik, P. 2012. Film and film development in Africa: overview and discussion. Arterial Network Conference on Creative Economy, Nairobi, December. http://www. arterialnetwork.org/uploads/2012/02/Peter_Rorviks_Presentation.doc.pdf (accessed < ২)

Shepperson, A. and K.G. Tomaselli. 2000. South African cinema beyond apartheid: affirmative action in distribution and storytelling. Social Identities 6(3): 323-343.

Thackway, M. 2003. Africa shoots back: alternative perspectives in sub-Saharan francophone African film. Bloomington, IN: Indiana University Press.

Tomaselli, K.G. 1980. Class and ideology: reflections in South African cinema. Critical Arts 1(1): 1-13.

Tomaselli, K.G. 1988. The cinema of apartheid: race and class in South African film. London and New York: Routledge.

Tomaselli, K.G. 2008. Paradigms in South African cinema research: modernity, the new Africa movement and beyond. Communicatio 34(1): 130-147.

Tomaselli, K.G. 2013. Film cities and competitive advantage: development factors in South African film. Journal of African Cinemas 5(2): 237-252.

Treffrey-Goatley, A. 2010. South African cinema after apartheid: a political-economic exploration. Communicatio 36(1): 37-57.

Ukadike, N.F. 1994. Black African cinema. California: University of California Press. 